\title{
Comment on: Nauck MA, Duran S, Kim D et al (2007) A comparison of twice-daily exenatide and biphasic insulin aspart in patients with type 2 diabetes who were suboptimally controlled with sulfonylurea and metformin: a non-inferiority study. Diabetologia 50:259-267
}

\author{
P. D. Home
}

Received: 13 February 2007 / Accepted: 15 February 2007 / Published online: 24 March 2007

(C) Springer-Verlag 2007

To the Editor: In their paper published in Diabetologia, Nauck and colleagues suggest that exenatide resulted in reductions in $\mathrm{HbA}_{1 \mathrm{c}}$ and low rates of hypoglycaemia similar to those observed with biphasic insulin aspart (30\% fastacting insulin aspart), though with marked differences in body weight trajectory (in favour of exenatide) and withdrawal rates (in favour of biphasic insulin aspart) [1]. However, the study is subject to serious shortcomings.

A fair comparison would have optimised both regimens; this appears to have been done for exenatide, as $80 \%$ of participants eventually received $10 \mu \mathrm{g}$ daily, in line with tolerance of this dose in earlier trials [2, 3]. However, insulin regimens, to a much greater extent than oral agents or exenatide, require appropriate insulin dose titration to achieve optimal blood glucose control. In this study, insulin dose adjustment was simply left to the investigator. It is not clear from the paper what intensity of follow-up, selfmonitoring, or dose adjustment to what target occurred, but at 52 weeks the premix insulin dose was only $24 \mathrm{U} /$ day, well below doses used in recent studies [4-8], and below doses normally encountered in clinical practice. This appeared not to be the result of hypoglycaemia in this particular group of patients - the reported hypoglycaemia rate was as low with insulin as with the glucagon-like peptide-1 mimetic.

The result of this is that the blood glucose control achieved was relatively poor in the insulin-treated group (a

P. D. Home $(\square)$

SCMS-Diabetes, The Medical School, Newcastle University,

Newcastle upon Tyne NE2 4HH, UK

e-mail: philip.home@ncl.ac.uk fall of $0.9 \%$ in $\mathrm{HbA}_{1 \mathrm{c}}$ from a baseline of $8.6 \%$ ) when compared with nearly all recently published treat-to-target studies with insulin therapy in people with type 2 diabetes [4-8]. In these, final $\mathrm{HbA}_{1 \mathrm{c}}$ is typically $<7.0 \%$ (achieved by $68 \%$ of participants in the INITIATE study [5], and eventually by $77 \%$ of participants in the 1-2-3 study, where a third premix injection was an option) [6]. The LanMet study achieved an $\mathrm{HbA}_{1 \mathrm{c}}$ of $7.1 \%$, but this was from baseline levels of $9.1 \%$ [8].

A similar problem bedevilled a previously published exenatide comparison with insulin, in which a change of $-1.1 \%$ from a baseline $\mathrm{HbA}_{1 \mathrm{c}}$ level of $8.3 \%$ was achieved with insulin glargine [3]; in the original treat-to-target study, Riddle and colleagues achieved a $45 \%$ greater reduction in $\mathrm{HbA}_{1 \mathrm{c}}$, from $8.6 \%$ at baseline to $7.0 \%$ [4]. Similar or better results were achieved with insulin detemir [7]. Again, there is a major difference in insulin dose: $47 \mathrm{U} /$ day in the Riddle study vs just $25 \mathrm{U} /$ day in the exenatide-glargine comparison study $[3,4]$.

The issue of appropriate comparators, and appropriate use of comparators, is critical to clinical trial designs of this type. In this study the pharmaceutical sponsors chose to use a competitor's insulin preparation as comparator to exenatide, when they have a very similar product on the market themselves. Was this an informed choice based on the expectation of rather poor results as a result of the study design?

Duality of interest P. D. Home has been advisor to the manufacturers of biphasic insulin aspart, insulin detemir and insulin glargine throughout their development. The manufacturer of exenatide has supported organisations with which the writer is associated. 


\section{References}

1. Nauck MA, Duran S, Kim D et al (2007) A comparison of twice-daily exenatide and biphasic insulin aspart in patients with type 2 diabetes who were suboptimally controlled with sulfonylurea and metformin: a non-inferiority study. Diabetologia 50: 259-267

2. DeFronzo RA, Ratner RE, Han J, Kim DD, Fineman MS, Baron AD (2005) Effects of exenatide (exendin-4) on glycemic control and weight over 30 weeks in metformin-treated patients with type 2 diabetes. Diabetes Care 28:1092-1100

3. Heine RJ, Van Gaal L, Johns D et al (2005) Exenatide vs insulin glargine in patients with suboptimally controlled type 2 diabetes. Ann Intern Med 143:559-569

4. Riddle MC, Rosenstock J, Gerich JE et al (2003) The treatto-target trial: randomized addition of glargine or human NPH insulin to oral therapy in type 2 diabetic patients. Diabetes Care 26:3080-3086

5. Raskin R, Allen E, Hollander $P$ et al (2005) Initiating insulin therapy in type 2 diabetes; a comparison of biphasic and basal insulin analogs. Diabetes Care 28:260-265

6. Garber AJ, Wahlen J, Wahl T et al (2006) Attainment of glycaemic goals in type 2 diabetes with once-, twice- or thrice-daily dosing with biphasic insulin aspart 70/30 (The 1-2-3 study). Diabetes Obes Metab 8:58-66

7. Hermansen K, Davies M, Derezinski T et al (2006) A 26-week, randomized, parallel treat-to-target trial comparing insulin detemir with NPH insulin as add-on therapy to oral glucose lowering drugs in insulin-naïve people with type 2 diabetes. Diabetes Care 29:1269-1274

8. Yki-Järvinen H, Kauppinen-Mäkelin R, Tiikkainen M et al (2006) Insulin glargine or NPH combined with metformin in type 2 diabetes: the LANMET study. Diabetologia 49:442-451 